\title{
Relatos sobre o Intercâmbio Brasil-Estados Unidos
}

\author{
Maitê Schmitz ${ }^{1}$
}

Normalmente, no início do curso de Direito, temos como leitura básica o livro "One I" ("Primeiro Ano"), em que Scott Turow narra os desafios e obstáculos enfrentados por um estudante de Direito nos Estados Unidos. O livro impressiona e assusta, pois o método de ensino, a relação estudante-professor, o grau de competitividade entre os alunos, bem como a carga de estudos difere sobremaneira da média no Brasil. Não que lá seja mais ou menos difícil; é diferente, e exige um ritmo muito diverso do existente aqui.

De julho a dezembro de 2003, tive a oportunidade de cursar um semestre de Direito nos Estados Unidos, graças a uma bolsa do governo brasileiro, proveniente do convênio FIPSE-CAPES, entre a Universidade Federal do Rio Grande do Sul (UFRGS), a Universidade Federal do Pará (UFPA), a Pace University e a University of Texas. Esse Programa tinha como tema a Responsabilidade Ambiental, mais especificamente, o Princípio da Precaução no Brasil e nos Estados Unidos. Juntamente com outros dois colegas da UFRGS e três do Pará, estudei na Pace University, que é considerada, nos Estados Unidos, a terceira melhor faculdade na área de Direito Ambiental. No primeiro mês, tivemos aulas de introduçăo ao sistema jurídico norte-americano ("Introduction to the American Legal System"), e de método de estudo e pesquisa em direito norte-americano ("Legal writing, reasoning and research"). Após essas aulas iniciais, cursamos um semestre regular de Direito, em que optei pelas disciplinas de Direito Ambiental Internacional ("International Environmental Law"), Direito Ambiental notte-americano ("Environmental Law: Skills and Practice"), Desenvolvimento Sustentável ("Wksp: Freedom \& Sub in 21 Century: Global Comparisons") e Direito Intemacional e Comparado sobre Refugiados ("International Comparative Refugee Law").

\footnotetext{
1 Estudante do último ano de Direito ne Universidade Federal do Rio Grande do Sul (UFRGS). Maitê de Souza Schmiz também estudou na Pace University (New York), durante o segundo semestre de 2003, com uma bolsa fornecida pelo governo brasileiro, Ministério da Educação (CAPES). A autora gostaria de agradecer à Profa. Dra. Cláudia Lima Marques pelo seu papel fundamental na concretizaçăo desse intercảmbio, pelo seu constante apoio, bem como peła oportunidade dada aos participantes de dividir com a comunidade acadêmica alguns dos resultados dessa experiência. Gostaria de agradecer, também, ao Programa de Pós-Graduação em Direito da UFRGS (PPGDir/UFRGS) e à CAPES pela oportunidade, e à Profa. Dra. Catherine Tinker por todo o apolo dado durante o semestre em Nova lorque.
} 
Em todas as disciplinas, era adotado o método socrático, com algumas variações. Consoante tal método, exige-se que os alunos se preparem previamente às aulas, fazendo as leituras indicadas para cada dia. Antes mesmo do início do período letivo, é disponibilizado um "syllabus", isto é, um programa com o conteúdo a ser abordado em cada aula, bem como as leituras obrigatórias e recomendadas para aquele dia. Dessarte, na aula, o professor promove a discussão do material já estudado, incentivando a reflexão sobre os temas. Isso facilita e aumenta a aprendizagen, uma vez que a leitura prévia faz com que os conteúdos sejam melhor fixados. Outrossim, tendo o básico já sido lido anteriormente, ao professor cabe aprofundar os pontos principais da matéria: ao invés de apenas recebermos informaçōes nas aulas, somos levados muito mais a refletir sobre elas, discuti-las e entendê-las por completo. Em uma das disciplinas ("International Environmental Law"), cada aula continha um período em que se discutia um caso hipotético, envolvendo as matérias reservadas para aquele dia. Esse método foi excelente para a promoção do aprendizado, pois năo bastava ler as matérias do dia - dever-se-ia, também, analisá-las criticamente e aplicá-las ao caso concreto. Outra vantagem do método é fazer com que não se perca o contato com a matéria ao longo da semana. Isso porque as leituras são em grande quantidade, de modo que se fazia mister dispensar um tempo diário para cada disciplina.

Entretanto, além da vasta carga de leituras, havia uma grande pressão sobre cada estudante. $O$ método socrático tem como principal característica a aula dialogada: o professor não expõe a matéria, mas questiona os alunos sobre ela. $O$ professor parte do pressuposto que todos leram o material indicado e, por isso, escolhe alguns estudantes para responderem a questões sobre esse material. Assim, devíamos estar sempre muito preparados em cada aula, para poder responder às perguntas caso o professor nos perguntasse diretamente, ou mesmo para poder participar das aulas. Isso porque, em turmas pequenas, todos participam, e o professor tem como função justamente incentivar essa discussão sobre os temas propostos para aquele dia.

Não houve uma disciplina em que o programa constante no "syllabus" não tenha sido completamente cumprido. Assim, posso afirmar que os objetivos das disciplinas foram totalmente alcançados. É importante mencionar, também, que as disciplinas "Introduction to the American Legal System" e "Legal Writing, reasoning e research" tinham como principal objetivo preparar o estudante estrangeiro para acompanhar o curso em geral. Tal objetivo foi igualmente alcançado do forma plena. As aulas das referidas disciplinas foram de extrema valia para o acompanhamento das demais matérias, facilitando a adaptação a sistema tão diverso do que temos no Brasil.

As referências bibliográficas das disciplinas eram sempre atualizadas, contendo artigos e casos inclusive de 2003. A maioria do material básico dos cursos consistia em apostilas montadas pelo próprio professor que ministrava a 
disciplina, de modo que o material era específico para a matéria, contendo os desenvolvimentos mais atuais sobre o tema. Em "International Environmental Law", por exemplo, as fontes indicadas freqüentemente abordavam questöes que hoje estão sendo amplamente discutidas, com diversas visões sobre o assunto. $O$ mesmo ocorreu com International Comparative Refugee Law, em que, a título exemplificativo, foram utilizados textos e decisoes judiciais (casos) sobre os efeitos que os acontecimentos de 11 de setembro de 2001 tiveram sobre o número de refugiados e imigrantes aceitos e rejeitados nos Estactos Unidos. Também foram colocados casos de 2002 e 2003 no material de "Environmental Law: Skills and Practice", com ampla bibliografia sobre as mudanças que determinadas decisões recentes da Suprema Corte estavam ocasionando no direito ambiental norteamericano. Além de materiais extremamente atualizados, na disciplina de "Wksp: Freedom \& Sub in 21 Century: Global Comparisons", a professora também complementava a aula com notícias da imprensa e informaçōes em geral obtidas em seminários ocorrendo contemporaneamente ao curso.

O método de avaliação variava conforme a disciplina e os objetivos a serem nela alcançados. Em "Introduction to the American Legal System", a avaliação consistia somente num exame final, no qual toda a matéria estudada deveria ser aplicada no caso concreto. Isto é, era dado um problema hipotético, no qual os alunos eram solicitados a indicar as questóes de direito envolvidas, apontar as possíveis soluçōes, indicando quais seriam as mais apropriadas e porque. Outra disciplina em que foi realizado exame final foi "Environmental Law: Skills and Practice". Nela, porém, o exame continha diversas questões, que podiam ser tanto teóricas quanto casos concretos. Além do exame, os alunos também elaboraram três trabalhos ao longo do curso, os quais também fizeram parte da avaliaçäo. Em "Legal writing, reasoning and research", a avaliação se baseava en diversos pequenos trabalhos entregues ao longo das aulas, bem como numa apresentação oral ao final do curso. $O$ método de avaliação era extremamente adequado aos objetivos do curso. Exemplificando: após uma aula ensinando a pesquisar legislação federal, tínhamos que entregar uma pesquisa em legislação federal. Assim, para cada matéria, havia um exercício a ser entregue e avaliado. Após a avaliação, a professora conversava individualmente com os alunos, a fim de explicar as falhas e fazer sugestões, de modo que a avaliação tambétn favorecia a evolução que deve ter o aluno ao longo do curso. Nas demais disciplinas, a avaliação consistiu basicamente na entrega de um trabalho final sobre um tema pertinente, mas à escolha do aluno. Ao longo do curso, deveriam ser entregues alguns materiais atinentes ao trabalho em desenvolvimento, como título, tópicos a serem abordados, estrutura do trabalho, bibliografia pesquisada, entre outros. Em duas disciplinas, também foi avaliada uma apresentação oral sobre o tema desenvolvido no trabalho.

É importante ressaltar, ainda sobre métodos de avaliação, que a regra é o anonimato. Ou seja, não se colocam nomes nas provas, sendo uma infração grave 
tentar identificar por qualquer meio o exame ou trabalho. Qualquer trabalho que conte para a avaliação do estudante não é entregue diretamente ao professor, mas sim à Secretaria, que identifica o material com um número. Isso evita que o professor, no momento da correção, leve em consideração qualquer outro fator além do material que está sendo por ele corrigido, o que resulta num resultado mais justo e imparcial. Em algumas disciplinas, porém, não era mantida a regra do anonimato, pois nelas o professor acompanhava o desenvolvimento dos trabalhos individualmente, fazendo uma orientação direta de cada aluno, de modo que os trabalhos entregues não precisavam ser anônimos.

Por fim, é imprescindivel frisar que a distribuição dos conceitos, independentemente da disciplina ou do método adotado, é sempre feita por "curva". Isso significa que os conceitos $(A, B, C, D, F)$ são distribuídos em determinada porcentagem, comparativamente. Assim, mesmo antes de realizada qualquer avaliação, já se sabe que apenas $\mathrm{X} \%$ dos alunos receberão conceito $\mathrm{A}$, outros $\mathrm{X} \%$ receberão $\mathrm{B}$, e assim por diante. Com isso, não basta acertar, por exemplo, todas as questōes de uma prova - caso todos os alunos acertem, irão ficat com conceito A aqueles que melhor responderem-nas, dentro da porcentagem previamente estabelecida.

Outro fator importante a se destacar é a diversidade e a quantidade de atividades didático-pedagógicas oferecidas pela Universidade. Como fazíamos parte do prograna de intercâmbio, com ênfase no estudo de direito ambiental e desenvolvimento sustentável, o núcleo responsável por esse tema na universidade (sobretudo na "Law School") proporcionava diversas atividades pertinentes ao programa. Em horários em que não havia aula, como em alguns fins-de-senana, eram realizadas caminhadas e visitas a locás que foram marcos na história da proteção ambiental nos Estados Unidos. Cada atividade contava com o acompanhamento de professores ou profissionais especialistas no assunto, os quais passavam muitas informações sobre o que estava sendo visto.

Ademais, os professores estavam sempre disponiveis para esclarecer dúvidas sobre a matéria e orientar os alunos de modo geral. Em horários alternativos às aulas, os estudantes podiam encontrar facilmente os professores nas suas salas, localizadas na própria faculdade. A faculdade, por sua vez, contava com excelente infra-estrutura. Uma grande vantagem, por exemplo, era o sistema de pesquisa de decisões jurídicas, artigos e até mesmo livros a que tínhamos disposição. A impressão desse material de pesquisa era gratuita e ilimitada, facilitando enormemente a coleta de material e a realização dos trabalhos. A biblioteca continha um grande acervo, sendo constantemente atualizada com novas obras. A infra-estrutura das salas de aula também era excelente: estas se assemelhavam a anfiteatros, facilitando a interação entre aluno e professor.

Por sermos estrangeiros, tivemos todo um cuidado especial a nós destinado. Isso facilitou incrivelmente a adaptação e a integração com estudantes, professores 
e funcionários. Éramos constantemente convidados para os diversos eventos promovidos pela faculdade e pelas organizações formadas pelo seu grupo de alunos.

Definitivamente, recomendo a Pace University a novos bolsistas brasileiros, sobretudo para aqueles que têm interesse na preservação do meio ambiente e no desenvolvimento sustentável. A Pace University tem um dos melhores programas de Direito Ambiental dos Estados Unidos, sendo mundialmente teconhecida nessa área. Conta com corpo docente atualizado e extremamente qualificado para a matéria, além de biblioteca completa sobre o assunto. Outrossim, por não ser uma universidade grande demais, a Pace University atende de modo individualizado cada um dos seus alunos, sobretudo os estrangeiros. Nesse sentido, a receptividade é enorme, principalmente aos estudantes brasileiros. A Pace University tem outros progranas com o Brasil, e uma vez ao ano promove, para seus estudantes $e$ professores, uma visita ao nosso país.

Ao final, posso aftrmar que a experiencia foi extremamente válida. Realmente, o método é muito diferente do que temos no Brasil; a barteira do idioma existe; há diversos desafios a serem superados; a competitividade entre os estudantes de uma mesma turma é grande; enfim, o cenário pintado por Scott Turow em "One L" não difere totalmente da realidade. Todavia, embora esse quadro talvez assuste num primeiro instante, uma vez imerso no sistema, qualquer estudante pode, com seu esforço pessoal, superar os obstáculos e fazer um bom curso. Percebi que o estudante brasileiro não está atrasado, não sabe menos, nem tem dificuldades muito maiores que os estudantes norte-americanos.

Equanto ao programa, enfim, posso afirmar que este foi completo, e permitiu um. aprendizado muito intenso não somente dos Estados Unidos, mas sobretudo do Brasil. Isso porque os problemas ambientais enfrentados pelo Brasil eram constantemente abordados em aulas de direito ambiental, e discuti-los com pessoas com diferentes visóes sobre o tema foi fundamental para entender melhor a situação. $O$ estudo comparativo que foi proporcionado e realizado permitiu que compreendêssemos melhor os problemas nacionais, de modo a serem buscadas novas soluções e novos caminhos. Também permitiu que vislumbrássemos as qualidades do Brasil, muitas até impensadas, sobretudo quanto ao seu sistema jurídico. Como bolsistas do governo, por toda a confiança em nós depositada, sabemos da responsabilidade social que temos hoje. E acredito que esse venha a ser o maior resultado do intercâmbio: a propagação do conhecimento adquirido, o maior diálogo entre as pessoas de diferentes naços, a aplicação do que foi aprendido em projetos que visem à maior proteção ambiental e ao maior desenvolvimento do Brasil. Agradeço à CAPES, aos coordenadores brasileiros e norte-americanos do Programa, bem cono a todos que participaram dessa empreitada. Com certeza, houve vários desafios; mas estes foram por muito superados pelos resultados positivos do Programa, para o qual concorreran todos que dele participaram. 